\title{
Applications of surface analysis in the environmental sciences: dehalogenation of chlorocarbons with zero-valent iron and iron-containing mineral surfaces
}

\author{
Molly M. McGuire ${ }^{\mathrm{a}, \mathrm{b}}$, Daniel L. Carlson ${ }^{\mathrm{b}}$, Peter J. Vikesland ${ }^{\mathrm{b}}$, \\ Tamar Kohn ${ }^{\mathrm{b}}$, Adam C. Grenier ${ }^{\mathrm{b}}$, Laura A. Langley ${ }^{\mathrm{a}}$, \\ A. Lynn Roberts ${ }^{\mathrm{b}}$, D. Howard Fairbrother ${ }^{\mathrm{a}, *}$ \\ a Department of Chemistry, The Johns Hopkins University, 3400 North Charles Street, Baltimore, MD 21218, USA \\ ${ }^{\mathrm{b}}$ Department of Geography and Environmental Engineering, The Johns Hopkins University, \\ 3400 North Charles Street, Baltimore, MD 21218, USA
}

Received 14 October 2002; accepted 16 October 2002

\begin{abstract}
Halogenated organic compounds are common pollutants in groundwater. Consequently, there is widespread interest in understanding the reactions of these compounds in the environment and developing remediation strategies. One area of ongoing research involves the reductive dechlorination of organohalides with zero-valent metals or metal sulfide minerals. These processes have been studied almost exclusively from the perspective of the aqueous phase. In this paper we illustrate the utility of surface analysis techniques, including electron spectroscopies, vibrational spectroscopies, and atomic force microscopy in elucidating the roles played by the surface. A dual analysis approach to the study of reductive dechlorination, combining traditional solution phase analysis with surface analytical techniques, also is demonstrated using a liquid cell coupled to an ultrahigh vacuum surface analysis chamber.
\end{abstract}

(C) 2003 Elsevier B.V. All rights reserved.

Keywords: Surface analysis; Auger electron spectroscopy; X-ray photoelectron spectroscopy; Vibrational spectroscopy; Atomic force microscopy; Iron; Organohalide; Remediation

\section{Introduction}

Water-solid interfaces play a key role in numerous processes of environmental importance. Dissolution and precipitation of mineral phases, adsorption of inorganic and organic species, electron transfer, photochemical processes, and microbial mediation all involve the interface between an aqueous solution and

\footnotetext{
* Corresponding author. Tel.: +1-410-516-4328; fax: $+1-410-516-8420$.

E-mail address: howard@jhu.edu (D.H. Fairbrother).
}

a mineral surface [1-8]. The nature of the surface will control the activity of the solid phase as well as the adsorption characteristics of species from solution. An understanding of the chemical composition and structure of the solid surface is required in order to achieve a molecular-level mechanistic conceptualization of these processes and enhance our predictive powers. Consequently, traditional surface science tools are finding new applications in mineralogical and environmental studies.

One area of ongoing study involving the solid-water interface involves the fate of halogenated compounds 
in the environment. Organohalides comprise 17 of the 25 organic pollutants most frequently detected in US groundwater [9] and over half of the US Environmental Protection Agency's Priority Pollutant list [10]. Recent investigations into their reductive dehalogenation reactions with zero-valent iron [11-40] have led to the successful development of permeable reactive barriers employing $\mathrm{Fe}(0)$ for containment of contaminated groundwater $[41,42]$. In a process equivalent to corrosion, $\mathrm{Fe}(0)$ donates an electron to the organohalide, which thereby is reduced to form less highly halogenated products and halide ions in solution. Iron sulfide minerals also have been shown to reduce low molecular weight organohalides [43-48]; such reactions may play an important role in the natural attenuation of halogenated compounds in the environment.

Laboratory studies of reduction by zero-valent iron to date have investigated the kinetics of the dehalogenation reaction and probable mechanisms [11-14, 16-21,23,26,27,29-31,34,35,37-39,49-52], as well as the rate enhancement obtained with bimetallic reductants (consisting of a catalytic metal such as $\mathrm{Ni}$ or Pd plated onto the zero-valent iron) $[15,22,33$, 36,51,53-58]. Additional studies using column reactors and pilot-scale permeable reactive barriers in the field $[24,28,32,59,60]$ have examined the efficiency and longevity of $\mathrm{Fe}(0)$ barriers under operating conditions. With few exceptions [26,55], these studies have involved analysis of the solution by conventional "wet chemistry" tools such as gas chromatography and gas chromatography-mass spectrometry (GC-MS).

In this paper, we illustrate how surface analytical techniques, including Auger electron spectroscopy (AES), X-ray photoelectron spectroscopy (XPS), attenuated total reflection Fourier transform infrared spectroscopy (ATR-FTIR), micro-Raman spectroscopy, and atomic force microscopy (AFM) can be employed to investigate aspects of chlorocarbon reactions with zero-valent metal reductants and metal sulfides. Additionally, we demonstrate how a liquid cell coupled to an ultrahigh vacuum (UHV) chamber can be used to combine information about surface composition with measurements of reaction rates to develop a more complete picture of the liquid-solid interface. This approach provides an extremely powerful combination capable of elucidating processes pertinent to environmentally relevant liquid-solid interfaces.

\section{Surface analytical techniques}

\subsection{Electron spectroscopies}

X-ray photoelectron spectroscopy (XPS) and Auger electron spectroscopy (AES) provide information on the chemical composition of the surface by measuring the element-specific kinetic energy of the electrons ejected subsequent to excitation by either an X-ray or electron beam, respectively [61-63]. The inelastic mean free path of the ejected electrons limits the volume of the sample probed, and therefore both techniques are sensitive to species within the near-surface region of the sample. For $500 \mathrm{eV}$ electrons in a typical metal, $>80 \%$ of the detected signal will come from within $2 \mathrm{~nm}$ of the surface. The concentration profile of chemical species below the interface can also be obtained by employing ion sputtering in conjunction with either technique [64].

In addition to providing quantitative information about the sample surface, AES can be used for imaging studies. Because a well-focused incident electron beam can be raster-scanned across the sample surface, elemental maps can be created showing the spatial distribution of each element at the surface. The strengths of XPS are complementary to those of AES. Although XPS does not readily provide spatially resolved information, it is sensitive to the oxidation state of the chemical species. High-resolution scans of specific elemental regions provide a means to understand the chemical state of the surface species in addition to the elemental composition.

\subsubsection{Auger electron spectroscopy for characterization of bimetallic reductants}

Bimetallic reductants, consisting of palladium or nickel plated onto zero-valent iron, were characterized in order to better understand the relationship between surface composition and reactivity towards reductive dehalogenation of organohalides. The amount of the plated metal (both nickel and palladium) on the iron surface, as well as its distribution on the surface and through the near-surface region, was investigated using AES.

2.1.1.1. Experimental details. Auger spectra, elemental maps, and depth profiles were obtained with a Physical Electronics (Ф) 610 Scanning Auger 
Microprobe operating in an ultrahigh vacuum (UHV) chamber with a typical base pressure of $1 \times 10^{-8}$ Torr. Samples were probed using a $5 \mathrm{keV}$ electron beam operating with an emission current of $100 \mu \mathrm{A}$ at $30^{\circ}$ from the sample normal. Spectra and elemental maps were acquired using a beam raster size of $100 \mu \mathrm{m} \times 100 \mu \mathrm{m}$.

A $\Phi$ 04-303 differentially pumped ion gun $(3 \mathrm{keV}$, $25 \mathrm{~mA}$ ) in conjunction with the AES spectrometer was employed for the depth profiles using an Ar pressure within the gun of $15 \mathrm{mPa}$. The Ar pressure was held constant throughout all experiments in order to ensure equivalent sputtering rates. The gun was oriented approximately normal to the sample surface and focused to a $2 \mathrm{~mm} \times 2 \mathrm{~mm}$ spot. Data were acquired at $10 \mathrm{~min}$ intervals. The typical operating pressure within the UHV chamber during sputtering was $1 \times 10^{-7}$ Torr.

\subsubsection{Quantification of bimetallic metal loading.}

Fig. 1 presents the Auger spectra of three different samples of Ni-plated iron prepared by an electroless deposition technique involving exposure of iron powder to an aqueous solution of $\mathrm{NiCl}_{2}$. The iron samples corresponding to the spectra in Fig. 1(a) and (b) were prepared using the same $1.0 \mathrm{mM} \mathrm{NiCl}_{2}$ solution. Sample (a) was exposed for $1 \mathrm{~min}$ while sample (b) was exposed to the solution for $10 \mathrm{~min}$. Fig. 1(c) represents the spectrum of an iron sample that was exposed to a $100 \mathrm{mM} \mathrm{NiCl} 2$ solution for $10 \mathrm{~min}$. The AES spectra indicate that all three samples contain carbon $(264 \mathrm{eV})$, oxygen $(512 \mathrm{eV})$, iron $(596,650$ and $700 \mathrm{eV}$ ), and nickel (728 and $848 \mathrm{eV}$ ). The notable difference between the spectra is the relative intensity of the nickel peaks. The ratio of the peak-to-peak heights

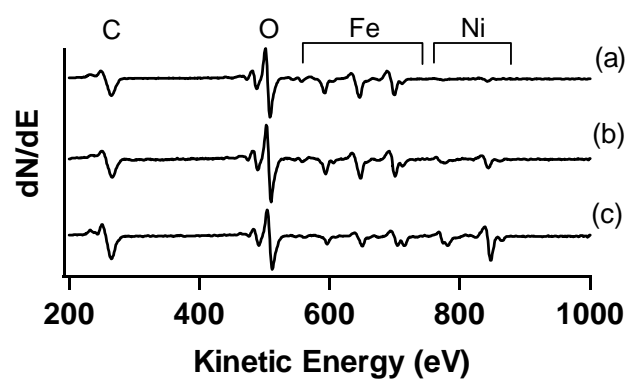

Fig. 1. Auger spectra of Ni-plated Fe powder. Samples were exposed to $1.0 \mathrm{mM} \mathrm{NiCl} 2$ for $1 \mathrm{~min}(\mathrm{a}), 10 \mathrm{~min}$ (b), and to $100 \mathrm{mM}$ for $10 \mathrm{~min}(\mathrm{c})$. of the differentiated nickel and iron peaks provides a quantitative measure of nickel loading. In this case, the percent composition of nickel on the sample surfaces is 9.6, 28.1 and $63.6 \%$ for Fig. 1(a)-(c), respectively. Quantitative characterization of the surface in these systems currently is being used to understand the relationship between nickel loading and the rate of dechlorination of cis-1,2-dichloroethene in batch reactor systems as measured by gas chromatography.

\subsubsection{Spatial distribution of catalytic metal with} AES imaging. Fig. 2 presents two elemental maps produced by AES imaging for a sample of nickel-plated iron. The two images were produced for the same $100 \mu \mathrm{m} \times 100 \mu \mathrm{m}$ area of the sample. The image on the left (Fig. 2(a)) shows the variation in the intensity of the iron Auger peak at $650 \mathrm{eV}$ as the beam was raster-scanned over the sample. Because the sample consists entirely of iron particles, the iron elemental map reflects the topography and spatial distribution of the particles. The image on the right (Fig. 2(b)) depicts the variation in the intensity of the nickel Auger peak at $848 \mathrm{eV}$ across the sample surface. As seen in this elemental map, nickel is distributed heterogeneously, appearing in localized patches on some iron grains, but not on others. Thus, it appears that the surface is not covered by a uniform layer of nickel, but rather is composed of a heterogeneous patchwork of nickel and iron. The heterogeneous distribution (islanding) of nickel is consistent with the fact the metal is being plated on an iron surface, which is itself composed of a heterogeneous oxide overlayer. Such information can be important in comparing the behavior of different systems employing bimetallic reductants because the dispersion of the catalytic metal on the base metal, in addition to the total loading, can affect reactivity [65].

\subsubsection{Depth profiles to determine surface availabil-} ity of plated metal. In addition to providing spatially resolved information across the iron surface, AES can be used to characterize the distribution of the catalytic metal as a function of depth below the surface. Fig. 3 illustrates the Pd:Fe ratio for two different palladized iron samples as a function of $\mathrm{Ar}^{+}$sputtering time. The sample corresponding to Fig. 3(a) was plated in a neutral solution of $\mathrm{K}_{2} \mathrm{PdCl}_{6}$, while the sample from Fig. 3(b) was plated in an acidic solution. 

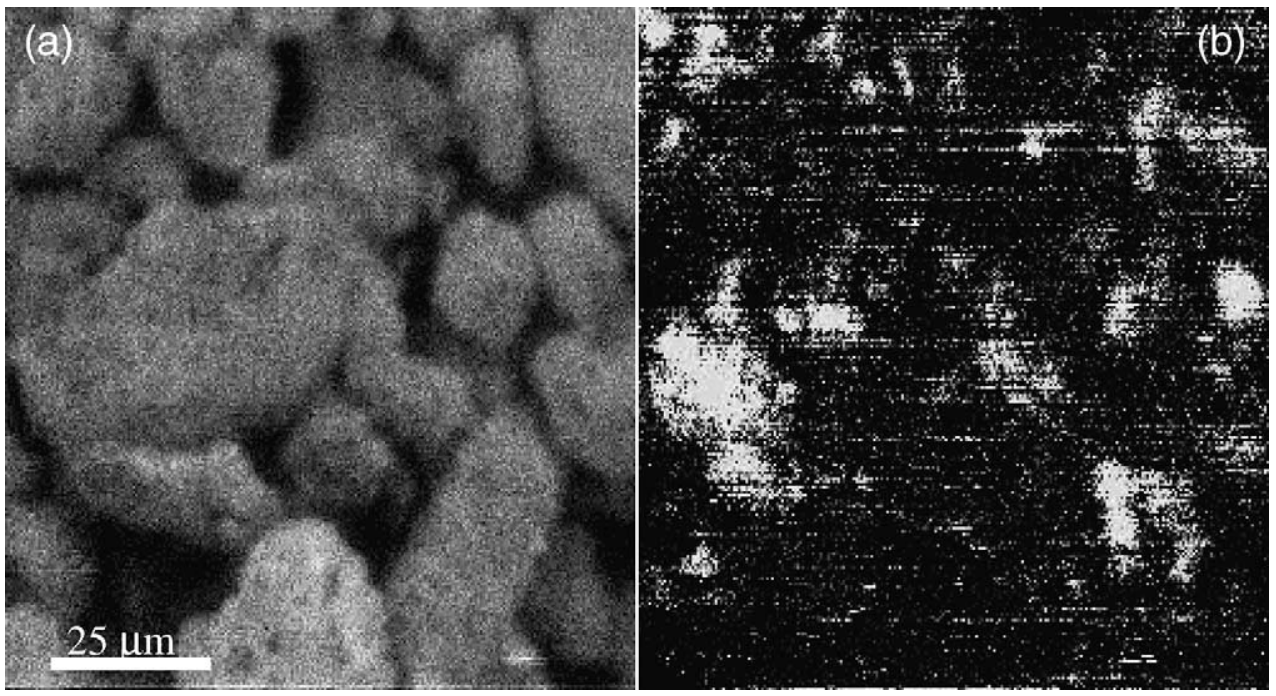

Fig. 2. Scanning AES elemental maps of $\mathrm{Fe}$ (a) and $\mathrm{Ni}$ (b) on a bimetallic reductant. Images correspond to the same $100 \mu \mathrm{m} \times 100 \mu \mathrm{m}$ area.

Auger spectra of the two samples before sputtering (data not shown) revealed that the $\mathrm{Pd}$ :Fe ratio of sample (a) was more than an order of magnitude greater than the ratio obtained from sample (b). The depth profile in Fig. 3(a) indicates that the Pd:Fe ratio decreases as the surface is sputtered, suggesting that the $\mathrm{Pd}$ is present at the surface of the iron particles and is removed as sputtering continues. In contrast, the depth profile in Fig. 3(b) shows that the Pd:Fe ratio initially increases through the first few sputtering cycles and then falls off. The shape of the profile shown in Fig. 3(b) suggests that the palladium does not reside at the surface of the bimetallic particle but is at least partially buried underneath an iron-containing overlayer. As a semi-quantitative comparison of the depth profiles, rough polynomial curve fits were performed on each profile in Fig. 3 (data not shown). Analysis of the resulting fits indicates that the integrated areas under the curves are equivalent within a factor of three, suggesting that the difference between these samples is the availability of the palladium at the surface, not the total amount plated. AES depth profiles have been used to explain differences in reactivity of $\mathrm{Pd} / \mathrm{Fe}$ particles as a function of preparation method [66]. The growth of iron oxides on bimetallic surfaces has been implicated previously in the finite lifetime of these bimetallic systems $[55,60]$. Depth profiles through the near-surface can provide direct evidence of the cause of this phenomenon: the reduced availability of the catalytic metal at the surface [66].

\subsubsection{X-ray photoelectron spectroscopy (XPS)}

2.1.2.1. Experimental details. Spectra were obtained with a Physical Electronics $(\Phi)$ 10-360 Precision Energy Analyzer using the $\mathrm{Mg} \mathrm{K} \alpha$ line (1253.6 eV) of a $\Phi$ 04-500 Dual Anode X-ray Source at $15 \mathrm{kV}$ and $300 \mathrm{~W}$. All spectra shown were obtained with a pass energy of $44.75 \mathrm{eV}$ and a resolution of $0.125 \mathrm{eV}$ per step. XPS analyses of Pd/Fe reductants in Section 2.1.2.2 were carried out in a UHV chamber with a base pressure of $2 \times 10^{-8}$ Torr. Binding energies for the $\mathrm{Pd} / \mathrm{Fe}$ spectra were referenced to the adventitious carbon 1s peak at $284.6 \mathrm{eV}$ [67]. XPS analyses of pyrite in Section 2.1.2.3 were carried out in a UHV chamber with a base pressure of $4 \times 10^{-10}$ Torr. Binding energies were referenced to the $\mathrm{S} 2 \mathrm{p}$ peak from the bulk pyrite disulfide species at $162.3 \mathrm{eV}$ [68]. A $\Phi$ 04-300 ion gun $(2 \mathrm{keV}, 25 \mathrm{~mA})$ was employed for the pyrite surface modifications using an Ar pressure within the gun of $15 \mathrm{mPa}$. The gun was oriented approximately $45^{\circ}$ to the sample surface and focused to a spot slightly larger than the area of the sample surface $(\sim 1 \mathrm{~cm} \times 1 \mathrm{~cm})$. 

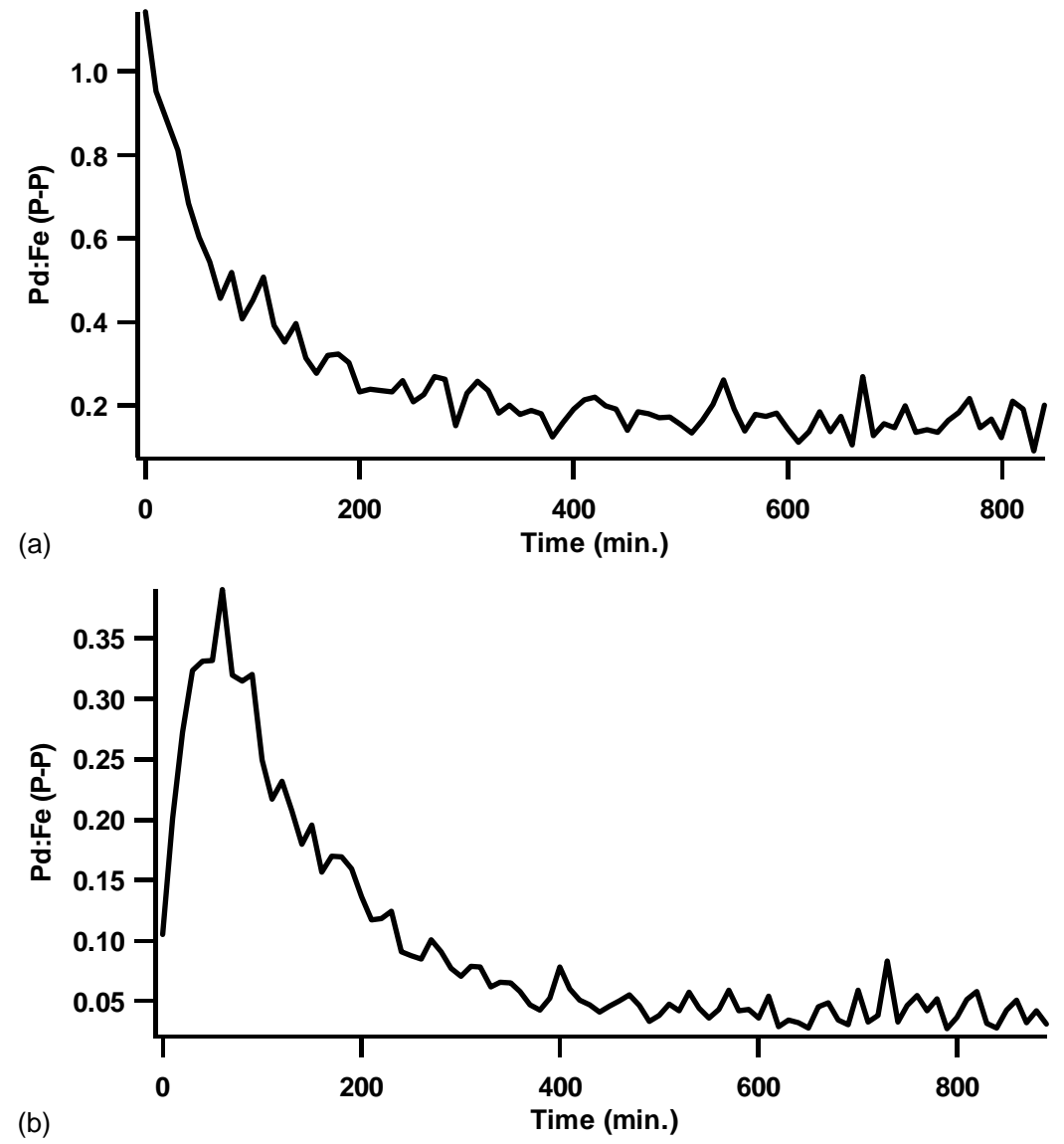

Fig. 3. Ratio (peak-to-peak heights of AES data) of the Pd signal to the Fe signal during depth profiles of two different bimetallic samples. The Pd signal decreases throughout the sputtering process on sample (a), but appears to increase over the first few sputtering cycles on sample (b) before decreasing at longer sputtering times.

\subsubsection{XPS for characterization of bimetallic reduc-} tants. The same palladium-iron bimetallic reductants discussed above were also examined by XPS. The resulting spectra of the $P d 3 d_{5 / 2}-3 d_{3 / 2}$ doublet are shown in Fig. 4. The position and widths of the peaks in the two spectra are very similar, suggesting that the oxidation state distribution of the palladium in the two samples is similar. Additionally, the position of the peaks at 340.1 and $335.1 \mathrm{eV}$ is in close agreement with previously reported values of the binding energies for $\operatorname{Pd}(0)$ [55]. Because only the zero-valent state of the palladium is expected to provide enhanced reactivity, such analyses can be invaluable to investigations of bimetallic reductants.

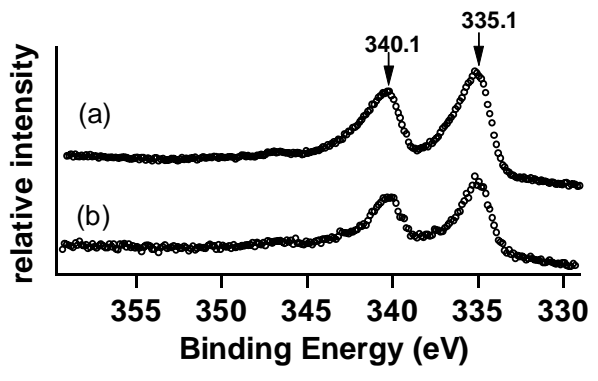

Fig. 4. XPS spectra of the Pd $3 d_{5 / 2}-3 d_{3 / 2}$ region for the same two samples in Fig. 3. Peak positions are indicative of $\operatorname{Pd}(0)$. 


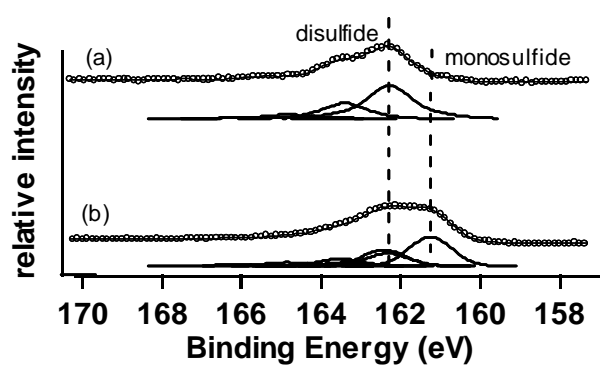

Fig. 5. The S(2p) XPS spectra of a natural pyrite (100) surface (a) and a surface that was $\mathrm{Ar}^{+}$ion-bombarded for $55 \mathrm{~min}$ (b).

\subsubsection{XPS for characterization of chemical speci-} ation at pyrite surfaces. The oxidation state information obtained from XPS is also useful in studying the chemical speciation of both $\mathrm{Fe}$ and $\mathrm{S}$ in pyrite. Previous studies have shown that specific surface defect sites exhibit enhanced reactivity towards water $[68,69]$. For the study of organohalide reactions with pyrite, surface modification by ion bombardment, together with a determination of the chemical speciation of the surface by XPS, can be used to create surfaces with known quantities of defects. Fig. 5 shows the $\mathrm{S} 2 \mathrm{p}$ region of two different pyrite samples. The top spectrum (Fig. 5(a)) is a natural pyrite (100) crystal face that was ultrasonically cleaned in methanol and acid-washed prior to introduction to the surface analysis chamber. The major contribution to this peak is the $2 \mathrm{p}_{3 / 2}-2 \mathrm{p}_{1 / 2}$ doublet of the disulfide species at 162.3 and $163.5 \mathrm{eV}$ [68]. After $55 \mathrm{~min}$ of sputtering with an $\mathrm{Ar}^{+}$ion gun, the bottom spectrum (Fig. 5(b)) is observed. Here a different peak shape is observed due to the contribution of the monosulfide species (sulfur vacancy sites) at lower binding energies of 161.5 and $162.7 \mathrm{eV}$ [68]. XPS data such as these provide a means of understanding which chemical species may be playing a role in subsequent reactions of the pyrite surface with organohalides in aqueous environments (see Section 2.4 below).

\subsection{Vibrational spectroscopies}

Infrared absorption and Raman spectroscopies have found widespread use in the study of bulk samples for decades and are applicable to the study of surface species as well [70]. By probing vibrational bands, these spectroscopies can be used to identify the chemical nature of adsorbed species and surface phases.
Although the penetration depth of the incident photons limits the surface sensitivity of both techniques, the choice of experimental geometry can favor surface specificity. The attenuated total reflection (ATR) geometry employed in the FTIR experiments described below makes it possible to selectively probe the surface of the iron sample placed in close contact with the ATR crystal. The evanescent wave generated by reflection of the infrared radiation at the internal surface of the ATR crystal penetrates only a few hundred nanometers into the sample [71]. The point-contact capabilities of the ATR accessory allows for analysis of small particles as well as larger coupons or foils.

Raman scattering is inherently a weak process, which makes the study of a small number of surface species difficult. The use of modern charge-coupled device (CCD) detectors, however, can compensate for the low sensitivity of the technique. One advantage of Raman spectroscopy is the ability to probe low frequency vibrations that are inaccessible with infrared absorption techniques. For example, bonds involving metallic species, such as the $\mathrm{Fe}-\mathrm{O}$ bonds in iron oxides, can be probed. Additionally, micro-Raman spectroscopy can be employed in spatially resolved studies by coupling the Raman spectrometer with a microscope.

\subsubsection{Attenuated total reflection Fourier transform infrared spectroscopy}

2.2.1.1. Experimental details. Spectra were acquired on a Mattson Infinity Series FTIR with a mercury cadmium telluride detector at a resolution of $2 \mathrm{~cm}^{-1}$. Surfaces of iron coupons goodfellow were examined by means of an attenuated total reflection device (SpectraTech Thunderdome) employing a germanium crystal in point-contact mode. Spectra were created by background subtraction of an unreacted iron coupon.

2.2.1.2. ATR-FTIR for monitoring silica uptake by zero-valent iron. One area of ongoing research in the study of permeable reactive barriers is the effect of common constituents of groundwater on the longevity of the barrier [24,32,59]. For example, adsorption of large quantities of silica may affect the reactivity of iron-based barriers over time. Consequently, the kinetics of silica adsorption on granular iron must be understood. 
Silica $\left(\mathrm{SiO}_{2}\right)$ uptake by iron coupons in buffered solutions that simulate groundwater was monitored by ATR-FTIR. Because the $\mathrm{Si}-\mathrm{O}$ stretch has a strong IR absorbance near $1000 \mathrm{~cm}^{-1}$, FTIR is very sensitive to the presence of silica. Point-contact mode attenuated total reflection FTIR, which brings solid surfaces into intimate contact with the ATR crystal, is ideally suited to studying the chemical species present on an iron coupon. Fig. 6 illustrates the spectra obtained from iron coupons removed from a $100 \mathrm{mg} / \mathrm{S} \mathrm{SiO}_{2}$ solution and rinsed after 1 day and 7 days. For comparison, a spectrum of albite, $\mathrm{NaAlSi}_{3} \mathrm{O}_{8}$, also is shown. Although $\mathrm{Si}-\mathrm{O}$ absorbance can be seen after 7 days of exposure of the $\mathrm{SiO}_{2}$ solution to the iron foil, the peak shape is differs from that observed from albite as a result of the dissimilar chemical environments of the $\mathrm{Si}-\mathrm{O}$ species in the silica adsorbed to the iron foil compared to the silicate mineral. As illustrated by the in-

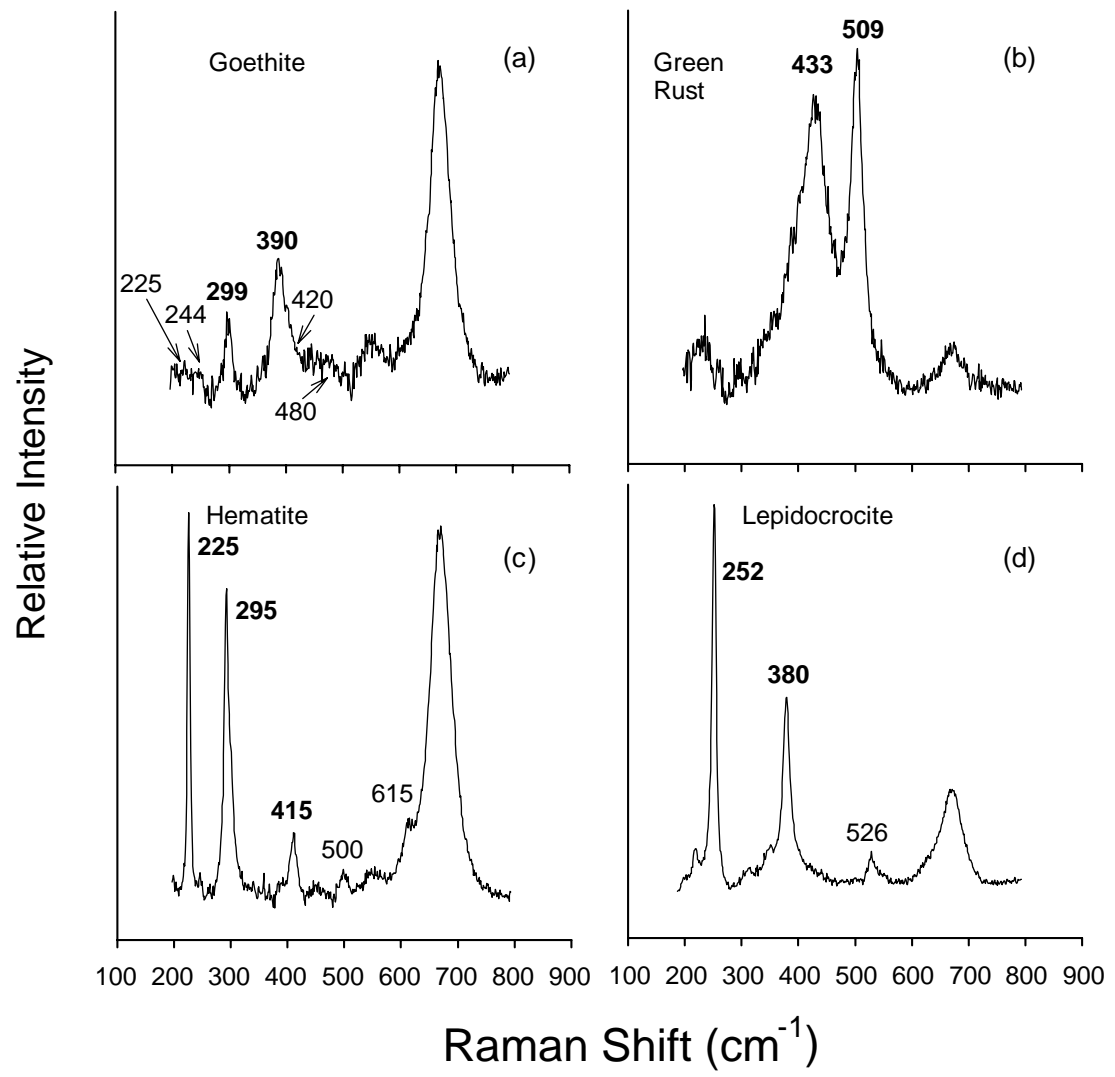

Fig. 7. Raman spectra of different iron grains removed from a laboratory-scale column reactor. Although none of the spectra represents a single crystalline iron oxide phase, the spectra indicate the presence of goethite $(\alpha-\mathrm{FeOOH})$ (a), green rust (mixed $\mathrm{Fe}(\mathrm{II})-\mathrm{Fe}(\mathrm{III})$ layered double hydroxide compounds) (b), hematite $\left(\alpha-\mathrm{Fe}_{2} \mathrm{O}_{3}\right)(\mathrm{c})$, and lepidocrocite $(\gamma-\mathrm{FeOOH})(\mathrm{d})$. 


\subsubsection{Micro-Raman spectroscopy}

2.2.2.1. Experimental details. Raman spectra were acquired on a Renishaw 1000 Raman microscope system consisting of an Olympus microscope, a spectrograph fitted with holographic filters, and a Peltier-cooled CCD detector. The $632.8 \mathrm{~nm}$ line of a Melles Griot $35 \mathrm{~mW}$ HeNe laser was used for excitation. The focused laser spot size was approximately $2 \mu \mathrm{m}$ in diameter.

\subsubsection{Micro-Raman spectroscopy for oxida-} tion product identification. As mentioned in Section 2.1.1.4, the formation of oxides on iron particles can have a significant impact on reductive dehalogenation by bimetallic particles $[55,60]$. It has also been speculated that semiconducting iron oxides may play a role in organohalide reduction by granular iron [50,72]. For these reasons, identification of the specific iron oxide phases present on the surface may be important in understanding the factors controlling longevity of permeable reactive barriers. Micro-Raman spectroscopy has the ability to identify iron oxide phases based on the unique vibrational bands associated with each crystalline phase.

Fig. 7 presents Raman spectra from four separate point analyses of iron grains taken from a laboratoryscale column reactor [73]. Although none of the spectra is representative of a pure mineral phase because each spot analyzed contains a mixture of iron oxide precipitates, each spectrum reveals the presence of a unique iron oxide phase within the probed volume. These can be assigned based on the position and relative intensity of the lines observed in the spectrum [74-76]. Specifically, goethite $(\alpha-\mathrm{FeOOH})$ is observed in Fig. 7(a), green rust (mixed valence Fe(II)-Fe(III) layered double hydroxide compounds) in Fig. 7(b), hematite $\left(\alpha-\mathrm{Fe}_{2} \mathrm{O}_{3}\right)$ in Fig. 7(c), and lepidocrocite $(\gamma-\mathrm{FeOOH})$ in Fig. $7(\mathrm{~d})$. These spectra illustrate the large variety of iron oxide phases formed as a result of the oxidation of the metal surface in a column reactor.

\subsection{Atomic force microscopy (AFM)}

Atomic force microscopy uses the interatomic forces between a cantilever-mounted tip and the

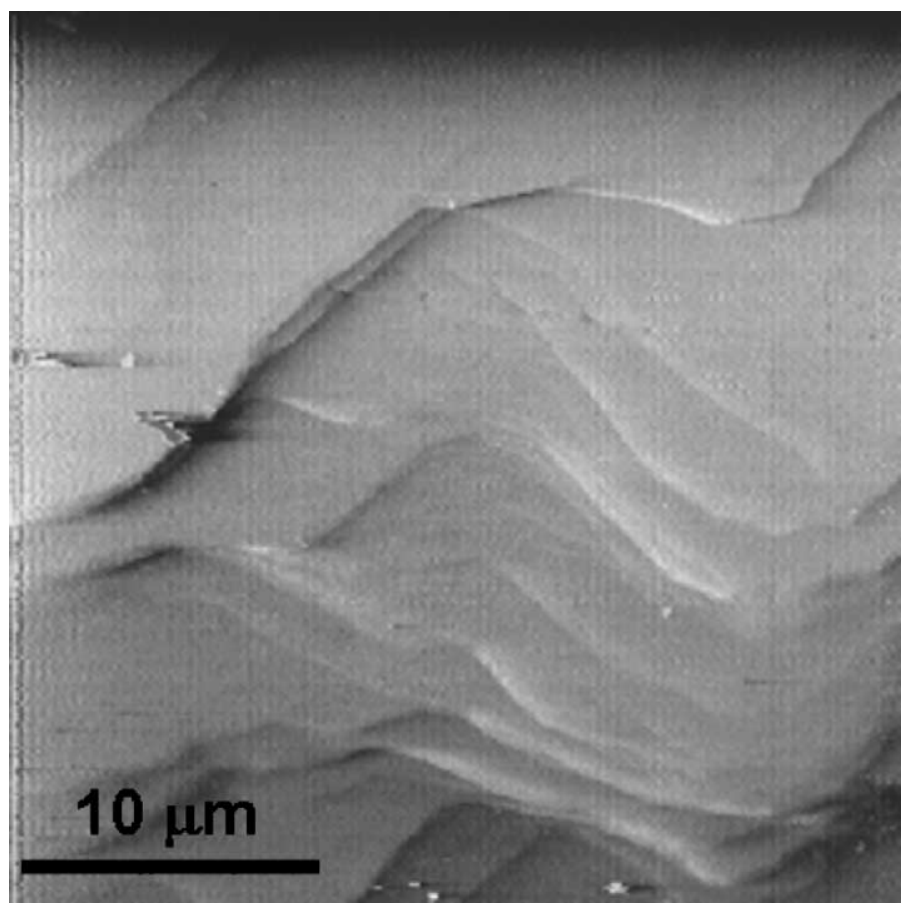

Fig. 8. AFM contact-mode force image of a pyrite (100) surface. The image corresponds to a $30 \mu \mathrm{m} \times 30 \mu \mathrm{m}$ area of the surface. 
sample surface to map out the topography of a surface [77]. Although this technique provides no means for chemical contrast or identification, it provides morphological information on length scales that can approach atomic resolution. Consequently, structural changes accompanying surface reaction (e.g. oxidation) can be examined.

\subsubsection{Experimental details}

AFM images were acquired in contact mode on a Burleigh Metris 2000NC atomic force microscope using a $\mathrm{Si}$ probe with a 1:1 conical tip (radius of approximately $100 \AA$ ). The resonant frequency of the tip was approximately $15 \mathrm{kHz}$ with a nominal stiffness of $0.1-0.34 \mathrm{~N} / \mathrm{m}$. A three-point plane removal filter was performed on each image prior to analysis.

\subsubsection{AFM for characterization of surface morphology}

The $\left(\begin{array}{lll}1 & 0 & 0\end{array}\right)$ surface of a pyrite single crystal is shown in Fig. 8. This natural surface is not atomically smooth, but rather is composed of a series of terraces separated by steps. Previous studies of the electronic structure of the pyrite $\left(\begin{array}{lll}1 & 0 & 0\end{array}\right)$ surface by scanning tunneling microscopy (STM) have suggested that step edges may be sites of enhanced conductivity, which could affect pyrite redox reactivity [78]. If step edges or other surface sites of higher reactivity are primarily responsible for reduction of organohalide species in solution, an examination of the morphological changes in the surface after exposure may offer clues about the nature of the reactive sites.

\subsection{UHV-coupled liquid cell for investigations of pyrite reactive sites}

All of the techniques mentioned above provide information about the nature of the reductant surface that is complementary to the traditional solution-phase analysis of the organohalide and its dehalogenation products for kinetic or mechanistic investigations. One limitation of these surface techniques, however, is the

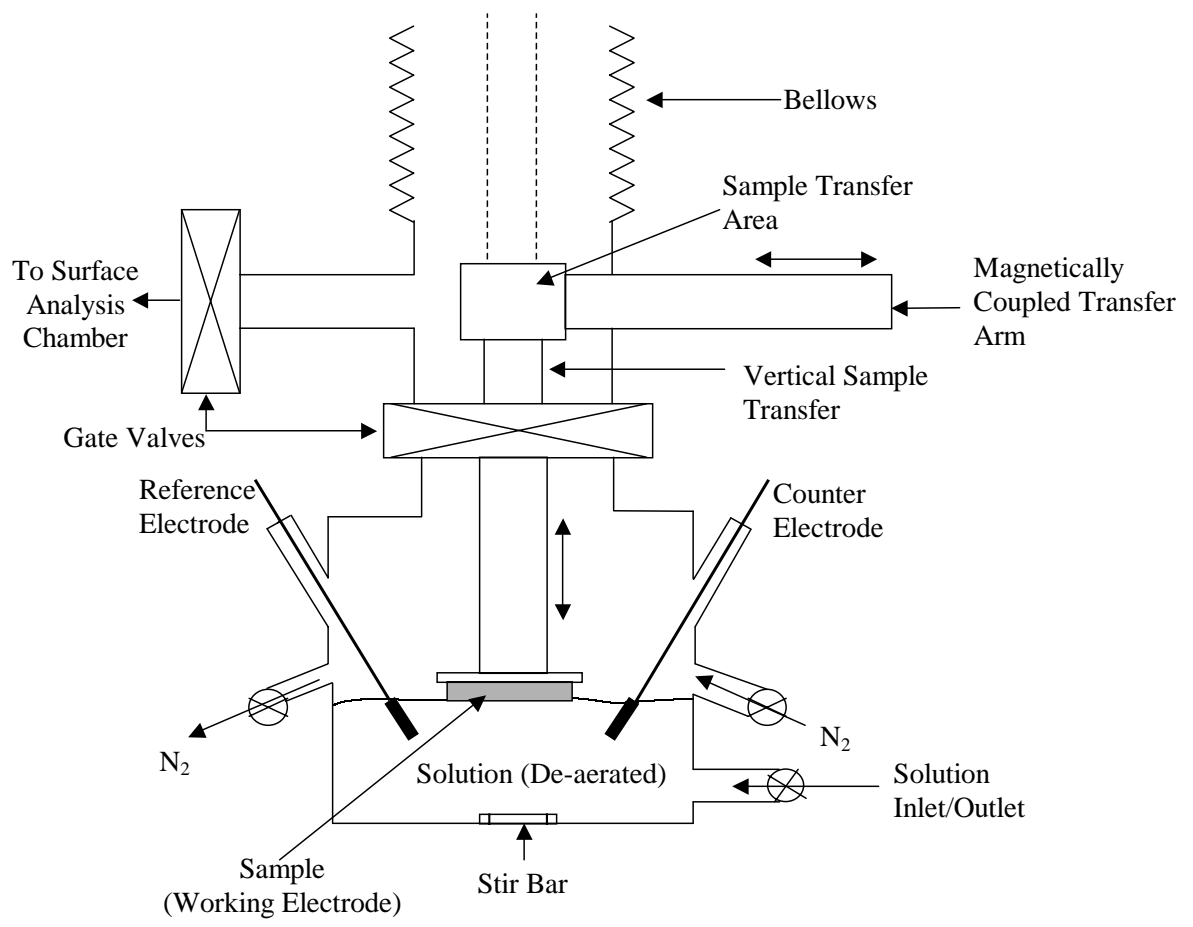

Fig. 9. Schematic of the UHV-coupled liquid cell. The sample can be transferred between the reaction solution and the UHV analysis chamber without exposure to atmospheric oxygen. An overpressure of $\mathrm{N}_{2}$ maintains the anoxic environment during reaction. The vertical transfer arm is electrically isolated, which allows the sample to be used as the working electrode in electrochemical experiments. Additional ports provide access for reference and counter electrodes. 
ex situ nature of the analyses. In each case, the sample is removed from (or returned to) the reaction medium and is exposed to the atmosphere during the transfer. This brings an added degree of uncertainty to the analysis because of the indeterminate effect of additional oxidation by atmospheric oxygen and water and contamination from background species.

One way to minimize this problem is to avoid exposing the sample to the atmosphere during the transfer to and from the surface analysis apparatus. Such a system has been developed to explore the relationship between surface composition and reactivity at the liquid/solid interface. A schematic of the experimental setup is illustrated in Fig. 9. A glass reaction vessel is coupled to an ultrahigh vacuum (UHV) chamber containing an XPS analysis system and an ion gun. When the system is open to the reaction vessel, the high-pressure side of the vacuum system is backfilled with nitrogen. The solution is deoxygenated prior to initiation of the reaction, and an overpressure of nitrogen in the reaction vessel maintains an anoxic environment throughout the course of the reaction. To perform a surface analysis, the sample is pulled up into the chamber, the gate valve to the reaction vessel is closed, and the high-pressure side of the vacuum system is pumped down by means of a combination of a membrane pump, sorption pump, and turbomolecular pump. The sample can then be transferred into the UHV environment for surface analysis. The sample may be moved back and forth between the reaction vessel and analysis chamber as often as desired without ever exposing the sample to the atmosphere. This approach also can be used to prepare model surfaces in the analysis chamber and to study their subsequent reactivity towards chlorocarbons in solution.

The experimental apparatus described above was used to investigate the effect of pyrite surface composition on the dechlorination reaction of the herbicide alachlor (2-chloro-2',6'-diethyl- $N$-(methoxymethyl)acetanilide). The UHV-coupled reaction vessel permitted creation of different surfaces with an $\mathrm{Ar}^{+}$ ion gun, characterization of the surface with XPS (see Fig. 5), and transfer of the sample to the reaction vessel containing the alachlor solution without introduction of atmospheric oxygen or water.

The natural and sputtered pyrite samples corresponding to the XPS spectra in Fig. 5 were each transferred in turn to the reaction vessel and solution
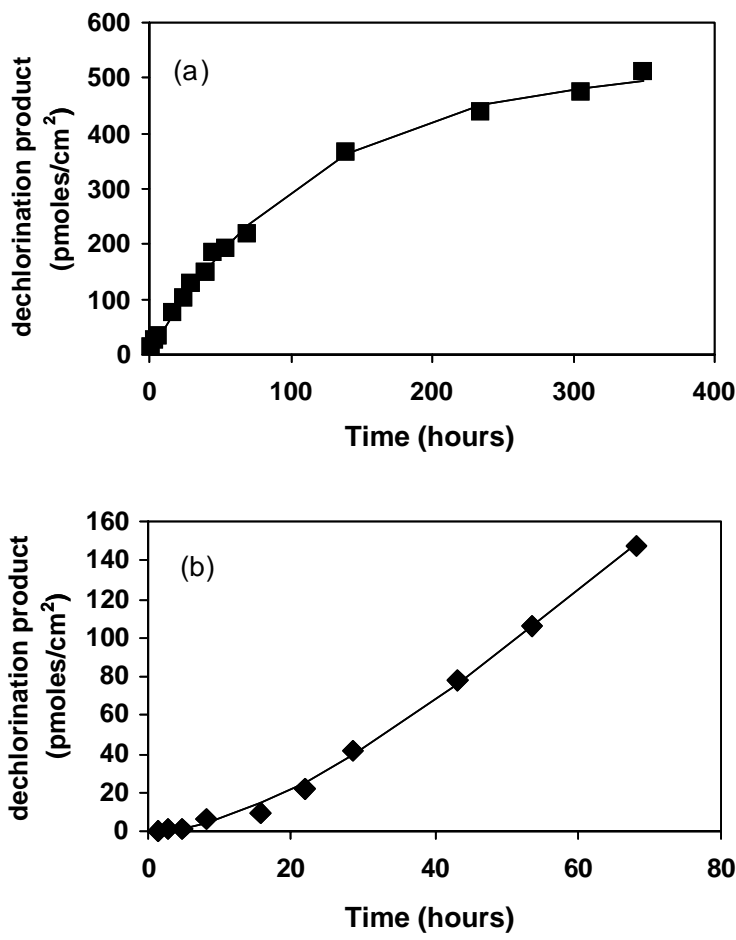

Fig. 10. Concentration of dehalogenation product over time upon exposure of an aqueous solution of alachlor to a natural pyrite (100) surface (a) and a surface with a significant number of sulfur-vacancy defect sites (b).

aliquots were removed over a period of days while the sample reacted. The appearance of the dechlorination product, 2', $6^{\prime}$-diethyl- $N$-(methoxymethyl)acetanilide (deschloroalachlor), was measured by gas chromatography-mass spectrometry (GC-MS). The concentration of deschloroalachlor as a function of time is plotted in Fig. 10 for each of the pyrite surfaces. As can be seen from the shape of these curves, the two surface compositions result in very different dechlorination kinetics. The natural surface (Fig. 10(a)) exhibits a decrease in reaction rate as a limited number of sites appear to become depleted over the course of the reaction. In contrast, the sputtered sample (Fig. 10(b)) exhibits an initial induction period at the beginning of the reaction, during which very little dechlorination is observed. That the monosulfide defects created by the sputtering process are consumed in the presence of water over a length of time equivalent to the induction period, together with the data presented in 
Fig. 10, suggests that these defects are not the sites responsible for the dechlorination of alachlor [79].

Current studies in our laboratory also are employing the UHV-coupled liquid cell in studies of the adsorption kinetics of silica, while future studies will combine electrochemical studies of chlorocarbon reduction in the cell with surface characterization. Thus, the UHV-coupled reaction vessel makes possible the union of traditional solution phase analysis and modern surface analytical techniques. Experiments such as the pyrite reactivity studies described above illustrate how information from both halves of the solid-solution interface can be brought together to more fully understand environmentally relevant redox processes.

\section{Conclusions}

All the surface analytical techniques discussed here are an integral component of our studies of reductive dehalogenation. By combining the surface characterization of the reductant with measurements of the reaction kinetics in the aqueous phase, this approach allows us to examine the influence of initial composition on observed reactivity trends, monitor adsorption phenomena, and explore the relationship between long-term performance of remediation technologies and surface evolution. The utility of this approach in our studies of the reactions of organohalides with metal and mineral surfaces suggests that surface analysis will continue to find many new applications in the environmental sciences.

\section{Acknowledgements}

The authors wish to thank Dr. R.W. Gillham at the University of Waterloo for use of the Raman system, and Dr. Lai Gui for production of the Pd:Fe bimetallic samples. The authors also wish to express their gratitude to Dr. Francois Reniers at the Université Libre des Bruxelles, Belgium for assistance with the liquid cell design, and the Materials Science Department at JHU for use of the surface analysis laboratory. This work was funded in part by the National Science Foundation (grant \#BES0086755), the Collaborative Research Activities in Environmental
Molecular Science (CRAEMS) initiative of the NSF (grant \#CHE0089168), the Environmental Protection Agency (grants \#R-82816401 and R-82877101-0-01), the Strategic Environmental Research and Development Program (SERDP) of the Department of Defense (grant \#DACA7299C008), and a National Science Foundation Graduate Research Fellowship for DLC.

\section{References}

[1] J.A. Davis, K.F. Hayes, Geochemical Processes at Mineral Surfaces, American Chemical Society, Washington, DC, 1986.

[2] M.F. Hochella, A.F. White, Mineral-Water Interface Geochemistry, Mineralogical Society of America, Washington, DC, 1990.

[3] W. Stumm, Chemistry of the Solid-Water Interface, Wiley/ Interscience, New York, 1992.

[4] C.P. Huang, C.R. O'Melia, J.J. Morgan, Aquatic Chemistry Interfacial and Interspecies Processes, American Chemical Society, Washington, DC, 1995.

[5] P.V. Brady, Physics and Chemistry of Mineral Surfaces, CRC Press, Boca Raton, FL, 1996.

[6] W. Stumm, J.J. Morgan, Aquatic Chemistry, 3rd ed., Wiley/Interscience, New York, 1996.

[7] J.F. Banfield, K.H. Nealson, Geomicrobiology: Interactions Between Microbes and Minerals, Mineralogical Society of America, Washington, DC, 1997.

[8] D.L. Macalady, Perspectives in Environmental Chemistry, Oxford University Press, Oxford, 1998.

[9] P.J. Squillace, M.J. Moran, W.W. Lapham, C.V. Price, R.M. Clawges, J.S. Zogorski, Environ. Sci. Technol. 33 (1999) 4176.

[10] USEPA, 40 CFR Part 131, 42159-42208, 1997.

[11] T. Senzaki, Y. Kumagai, Kogyo Yosui 357 (1988) 2.

[12] T. Senzaki, Y. Kumagai, Kogyo Yosui 369 (1989) 19.

[13] R.W. Gillham, S.F. O'Hannesin, Ground Water 32 (1994) 958.

[14] L.J. Matheson, P.G. Tratnyek, Environ. Sci. Technol. 28 (1994) 2045.

[15] R. Muftikian, Q. Fernando, N.E. Korte, Water Res. 24 (1995) 2434.

[16] K.D. Warren, R.G. Arnold, T.L. Bishop, L.C. Lindholm, E.A. Betterton, J. Hazard. Mater. 41 (1995) 217.

[17] T.L. Johnson, M.M. Scherer, P.G. Tratnyek, Environ. Sci. Technol. 30 (1996) 2634.

[18] W.S. Orth, R.W. Gillham, Environ. Sci. Technol. 30 (1996) 66.

[19] R. Allen-King, R.M. Halket, D.R. Burris, Environ. Toxicol. Chem. 16 (1997) 424.

[20] T.J. Campbell, D.R. Burris, A.L. Roberts, J.R. Wells, Environ. Toxicol. Chem. 16 (1997) 625.

[21] J. Gotpagar, E. Grulke, T. Tsang, D. Bhattacharyya, Environ. Prog. 16 (1997) 137.

[22] J.P. Fennelly, A.L. Roberts, Environ. Sci. Technol. 32 (1998) 1980. 
[23] T.L. Johnson, W. Fish, Y.A. Gorby, P.G. Tratnyek, J. Contam. Hydrol. 29 (1998) 379.

[24] S.F. O’Hannesin, R.W. Gillham, Ground Water 36 (1998) 164.

[25] US EPA, EPA/600/R-98/125, 1998.

[26] J. Gotpagar, S. Lyuksyutov, R. Cohn, E. Grulke, D. Bhattacharyya, Langmuir 15 (1999) 8412.

[27] W.F. Wust, R. Kober, O. Schlicker, A. Dahmke, Environ. Sci. Technol. 33 (1999) 4304.

[28] W.A. Arnold, A.L. Roberts, Environ. Eng. Sci. 17 (2000) 291.

[29] W.A. Arnold, A.L. Roberts, Environ. Sci. Technol. 34 (2000) 1794.

[30] T. Bigg, S. Judd, Environ. Technol. 21 (2000) 661.

[31] P. Burrow, K. Aflatooni, G. Gallup, Environ. Sci. Technol. 34 (2000) 3368.

[32] J. Farrell, M. Kason, N. Melitas, T. Li, Environ. Sci. Technol. 34 (2000) 514.

[33] Y. Kim, E. Carraway, Environ. Sci. Technol. 34 (2000) 2014.

[34] T. Dombek, E. Dolan, J. Schultz, D. Klarup, Environ. Pollut. 111 (2001) 21.

[35] T. Li, J. Farrell, Environ. Sci. Technol. 35 (2001) 3560.

[36] H.L. Lien, W.X. Zhang, Colloid Surf. A 191 (2001) 97.

[37] G.A. Loraine, Water Res. 35 (2001) 1453.

[38] E. Nyer, D. Vance, Ground Water Monit. Remediat. 21 (2001) 41.

[39] L.A. Totten, U. Jans, A.L. Roberts, Environ. Sci. Technol. 35 (2001) 2268.

[40] C. Geiger, N. Ruiz, C. Clausen, D. Reinhart, J. Quinn, Water Res. 36 (2002) 1342.

[41] EnviroMetal Technologies Inc., September 2002. http://www.eti.ca/.

[42] Permeable Reactive Barriers Action Team, Remediation Technologies Development Forum (RTDF), September 2002. http://www.rtdf.org/public/permbarr/barrdocs.htm.

[43] M.R. Kriegman-King, M. Reinhard, Environ. Sci. Technol. 28 (1994) 692.

[44] E. Lipczynska-Kochany, S. Harms, R. Miilburn, G. Sprah, N. Nadarajah, Chemosphere 29 (1994) 1477.

[45] E.C. Butler, K.F. Hayes, Environ. Sci. Technol. 32 (1998) 1276.

[46] E.C. Butler, K.F. Hayes, Environ. Sci. Technol. 33 (1999) 2021.

[47] E.C. Butler, K.F. Hayes, Environ. Sci. Technol. 34 (2000) 422.

[48] R. Weerasooriya, B. Dharmasena, Chemosphere 42 (2001) 389.

[49] A.L. Roberts, L.A. Totten, W.A. Arnold, D.R. Burris, T.J. Campbell, Environ. Sci. Technol. 30 (1996) 2654.

[50] T.M. Sivavec, P.D. Mackenzie, D.P. Horney, S.S. Baghel, in: Proceedings of the International Containment Technology Conference, St. Petersburg, FL, 1997.

[51] J.G. Doyle, T. Miles, E. Parker, I.F. Cheng, Microchem. J. 60 (1998) 290

[52] M.M. Scherer, B.A. Balko, D.A. Gallagher, P.G. Tratnyek, Environ. Sci. Technol. 32 (1998) 3026.

[53] C. Grittini, M. Malcomson, Q. Fernando, N. Korte, Environ. Sci. Technol. 29 (1995) 2898.
[54] E.L. Appleton, Environ. Sci. Technol. 30 (1996) 536A.

[55] R. Muftikian, K. Nebesny, Q. Fernando, N. Korte, Environ. Sci. Technol. 30 (1996) 3593.

[56] L. Liang, N. Korte, J.D. Goodlaxson, J. Clausen, Q. Fernando, R. Muftikian, Ground Water Monit. Remediat. 17 (1997) 122.

[57] T. Li, J. Farrell, Environ. Sci. Technol. 34 (2000) 173.

[58] D.W. Elliott, W.X. Zhang, Environ. Sci. Technol. 35 (2001) 4922.

[59] R.W. Gillham, S.F. O'Hannesin, M.S. Odziemkowski, R.A. Garcia-Delgado, R.M. Focht, W.H. Matulewicz, J.E. Rhodes, in: Proceedings of the International Containment Technology Conference, St. Petersburg, FL, 1997.

[60] T.M. Sivavec, P.D. Mackenzie, D.P. Horney, in: Proceedings of the National Meeting, Division of Environmental Chemistry, American Chemical Society, Washington, DC, 1997.

[61] J.H.D. Eland, Photoelectron Spectroscopy, Butterworths, London, 1974.

[62] T.A. Carlson, Photoelectron and Auger Spectroscopy, Plenum Press, New York, 1975.

[63] C.C. Chusuei, D.W. Goodman, Encyclopedia of Physical Science and Technology, 3rd ed., vol. 17, Academic Press, New York, 2002, p. 921.

[64] J.C. Riviere, S. Myhra, Handbook of Surface and Interface Analysis: Methods for Problem-Solving, Marcel Dekker, New York, 1998.

[65] V. Ponec, G.C. Bond, Catalysis by Metals and Alloys, Elsevier, Amsterdam, 1995.

[66] L. Gui, M.M. McGuire, D.H. Fairbrother, R.W. Gillham, J. Catal. B, submitted for publication.

[67] T.L. Barr, S. Seal, J. Vac. Sci. Technol. A 13 (1995) 1239.

[68] J.M. Guevremont, J. Bebie, A.R. Elsetinow, D.R. Strongin, M.A.A. Schoonen, Environ. Sci. Technol. 32 (1998) 3743.

[69] J.M. Guevremont, D.R. Strongin, M.A.A. Schoonen, Am. Mineral. 83 (1998) 1246.

[70] J.T. Yates Jr., T.E. Madey, Vibrational Spectroscopy of Molecules on Surfaces, Plenum Press, New York, 1987.

[71] J. Fahrenfort, Spectrochem. Acta 17 (1961) 698.

[72] M.M. Scherer, B.A. Balko, P.G. Tratnyek, in: D.L. Sparks, T.J. Grundl (Eds.), Mineral-Water Interfacial Reactions: Kinetics and Mechanisms, American Chemical Society, Washington, DC, 1998 , p. 301.

[73] P.J. Vikesland, T. Kohn, J. Klausen, W.P. Ball, A.L. Roberts, in preparation.

[74] T. Ohtsuka, K. Kubo, N. Sato, Corrosion 42 (1986) 476.

[75] D. Thierry, D. Persson, C. Leygraf, N. Boucherit, A. Hugot-LeGoff, 32 (1991) 273.

[76] P.M.L. Bonin, M.S. Odziemkowski, E.J. Reardon, R.W. Gillham, J. Solution Chem. 29 (2000) 1061.

[77] D. Sarid, Scanning Force Microscopy: With Applications to Electric, Magnetic, and Atomic Forces, Oxford University Press, Oxford, 1994.

[78] C.M. Eggleston, M.F. Hochella Jr., Am. Mineral. 77 (1992) 221.

[79] D.L. Carlson, M.M. McGuire, A.L. Roberts, D.H. Fairbrother, Environ. Sci. Technol. 37 (2003) 2394. 


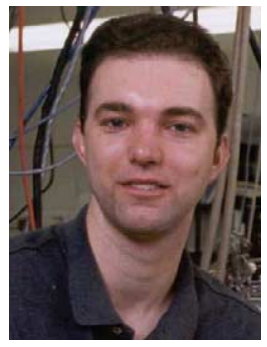

D. Howard Fairbrother received his BA from Oxford University, UK (1989) and $\mathrm{a} \mathrm{PhD}$ in physical chemistry from Northwestern University (1994), with Professors Peter Stair and Eric Weitz. Following a postdoctoral position working on aspects of atmospheric chemistry with Professors Gabor Somorjai and Harold Johnston at the University of California, Berkeley, he joined the Chemistry
Department at Johns Hopkins University in Baltimore in 1997. His main research interests are in the study of reactions at polymer surfaces including the chemistry of radical/surface interactions as well as mechanistic studies on environmental/atmospheric chemistry at solid surfaces and in thin films. He was a recipient of a Career award from the National Science Foundation in 2000. 